\title{
DETERMINANTES DOS SISTEMAS DE PLANEAMENTO E CONTROLE DA PRODUÇÃO
}

\author{
J.M. Vilas-Boas da Silva ${ }^{*}, * * *$ \\ e J.M.Kay
}

***Este artigo é dedicado a Maria da Graça Ferreira, pela generosidade com que sempre acreditou no meu trabalho.

Bem Haja. jvb.

\begin{abstract}
O estudo dos Sistemas de Planeamento e Controle da Produção (SPCP) tem revelado sérias preocupações com as elevadas percentagens de falha em funcionamento destes procedimentos. As práticas correntes, baseadas em abordagens operacionais, têm ignorado os objectivos estratégicos, têm-se mostrado incapazes de suportar as competências. -base do negócio, têm ignorado a avaliação do desempenho das soluções implementadas e são incapazes de prever a adequabilidade de potenciais soluçōes de SPCP.

Este artigo tem como propósito desenvolver um contexto estratégico para o posicionamento dos SPCP que possibilite uma abordagem contingencial, holistica, isenta e fiável. Consequentemente, será delineada uma perspectiva mais rica do problema que saliente as necessidades de consistência no processo de tomada de decisão e o cruzamento do saber proveniente de teorias rivais, relativamente às relaçōes entre os $S P C P$ e a estratégia do negócio, a estratégia para os sistemas de informação, a
\end{abstract}

\footnotetext{
${ }^{*}$ Docente da Escola Superior de Ciências e Tecnologia, PFF/CRB/UCP e Doutorando na CU, UK.

Professor of Manufacturing Systems Engineering and Head of the Manufacturing Systems Department, SIMS, Cranfield University, UK.
} 
estratégia de operações e a concepção da estrutura organizacional. $A$ abrangência desta perspectiva proporcionou uma base mais forte para se desenvolver um contexto analítico para o posicionamento dos SPCP que suportou o enunciado de proposições relativas às políticas para a concepção ou seleç̧ão e implementação dos SPCP.

\section{INTRODUÇÃO}

\section{Justificação do interesse do problema: abordagem clássica e lacunas}

A esmagadora maioria dos Sistemas de Planeamento e Controle da Produção (SPCP) são seleccionados ou concebidos e implementados com base em preocupações de carácter operacional, sujeitas às pressões inerentes à tomada de decisão no curto prazo e manifestadas no âmbito de um dado paradigma organizacional genérico, implicitamente considerado. Uma pesquisa bibliográfica prévia revelou basicamente três grandes tipos de lacunas:

i) Estratégicas. Muitas das decisões relativas aos SPCP são concretizadas numa base funcional e/ou improvisada (Hill, 1993: 35, 250) e dependentes do parecer dos fornecedores de soluções informatizadas (Porter et al, 1996), ignorando: as necessidades do negocio, as ligações ao contexto competitivo (Latham, 1981; Lockett, 1989; Rhodes, 1991, McAllister \& Carlisle, 1994) e a ausência da definição de uma métrica correcta, focada nos interesses do negócio, o que resulta num aumento do risco e dos custos incorridos (Primrose, 1990).

ii) Na especificação e concepção. Esta lacuna é caracterizada pela ausência de diferenciação dos critérios de concep̧̧ão para diferentes tipos de negócio (Orlicky, 1975:273; Rhodes, 1991; Hill, 1993:253-56; Henderson, 1997), uma deficiente especificação de compra ou de projecto dos SPCP (Lawrence, 1986) e pelo emprego de demasiada intuição e empirismo na concepção, selecção e avaliação de soluções (Ezingeard \& Grieve, 1995), entre outros aspectos. Por outro lado, os sistemas de PCP de suporte informático sofrem ainda dos problemas usuais de qualquer sistema de informação: dificuldades de definição dos problemas provenientes das ciências sociais (Martin, 1989:480; Smithson, 1989: 415), diferentes e conflituosas perspectivas dos problemas (Symons \& Walsham, 1989b: 426; Newell et al, 1991); especificações inconsistentes, incompletas e não-fiáveis (Rhodes, 1991), demasiadas restrições impostas pelos requisitos não-funcionais (Symons \& Walsham, 1989b: 425-26), 
ausência de foco e de personalização (Burgoyne, 1989: 5; Checkland, 1989: 38-89; Smithson, 1989: 415), ausência de simplificação dos processos antes da aplicação das tecnologias de informação (Hammer, 1990; Rhodes, 1991), entre outros.

iii) De implementação. Muitas vezes a fixação de critérios e a monitoria e avaliação dos SPCP ocorre depois da implementação. Também ocorre frequentemente uma falta de motivação e de sensibilização, quer dos grupos de implementação, quer das próprias organizações para a avaliação dos SPCP (McAllister \& Carlisle, 1994). Outros dos problemas encontrados dizem respeito à implementação dos sistemas de informação, nomeadamente uma deficiente comunicação e ausência de: liderança, orientação, compromisso da gestão e envolvimento dos utilizadores (Symons \& Walsham, 1989b: 425-26; Rhodes, 1991; Ohno \& Mito, 1988: 55). Neste capítulo foram ainda detectadas deficiências na formação e treino, bem como na qualidade e quantidade dos recursos humanos empregues e ainda, na ausência de procedimentos de garantia da qualidade (Symons \& Walsham, 1989b: 426; Millard, 1989). Finalmente, foram detectadas preocupações com a actualização das bases de dados e com a extrapolação de dados passados para o futuro (Dear, 1988: 67; Nanni et al, 1992; Burbidge, 1996: 91).

\section{Âmbito e propósito do trabalho de investigação}

O âmbito de um trabalho de investigação que proponha definir orientações para a concepção ou selecção e implementação das soluções de SPCP mais adequadas, na produção em lotes, poderá ser explicitado através do desenvolvimento de um contexto que enquadre a avaliação do desempenho de SPCP, tendo em conta as questões acabadas de enumerar. Consequentemente, a deteç̧ão dos determinantes das causas de falha e sucesso dos SPCP constituir-se-á como um elemento fulcral na identificação das condicionantes das políticas de gestão que permitam apoiar quem toma decisões sobre a selecção ou concepção e implementação de SPCP, o objectivo do trabalho. A Figura 1 representa o contexto descritivo que se definiu com base na pesquisa bibliográfica prévia e que suporta o contexto analítico que irá ser apresentado neste artigo para abordagem do problema identificado (Figura 4). Este contexto analítico permitirá, numa primeira fase, identificar os principais determinantes de uma política para os Sistemas de Planeamento e Controle da Produção. Este texto pretende identificar os principais aspectos a ter em consideração, face aos determinantes encontrados. 
Fig. 1

POSICIONAMENTO DOS SISTEMAS DE PCP

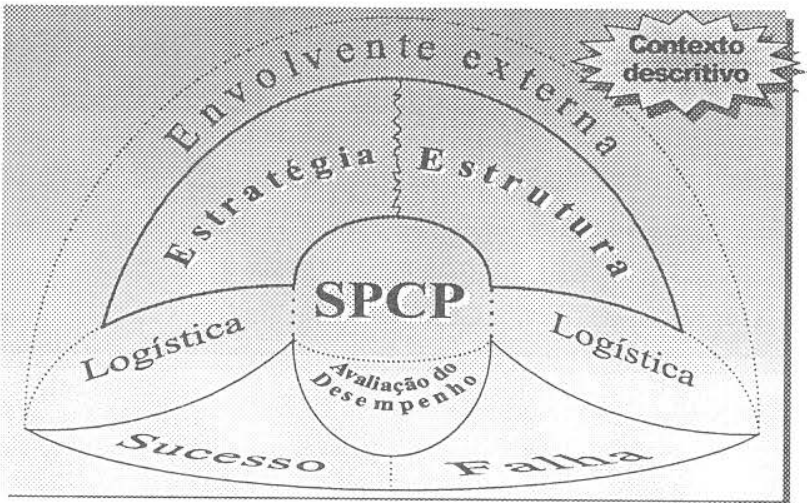

\section{Estado da arte}

Recentemente têm sido efectuados esforços de investigação exploratória, com vista à integração estratégica de práticas operacionais de controle da produção, objectivos do negócio e/ou prioridades competitivas (e.g., Davies et al, 1996), procurando ultrapassar o tradicional excesso de influência operacional na escolha de soluções para os SPCP. Contudo, estas abordagens, embora constituindo um avanço relevante para o conhecimento, pecam ainda por algumas omissões e limitações.

Primeiramente, são abordagens genéricas aos SPCP, desenvolvidas dentro das fronteiras do paradigma clássico, ignorando, quer as formas alternativas de planeamento e controle da produção (e.g., o Just-in-Time), quer a íntima relação dos SPCP com a forma de organização do sistema de fabrico (e.g., orientação para o processo versus orientação para o produto).

Em segundo lugar, ignoram que muitos dos problemas inerentes ao desempenho e eficácia dos SPCP podem residir fora da fronteira funcional tradicional do planeamento e controle da produção. Como tal, não questionam as influências das áreas de conhecimento a montante, nem perspectivam o problema de planeamento e controle do sistema produtivo no âmbito da estruturação e concepção da organização, preterindo a abordagem holística em favor de uma outra reducionista.

Por outro lado, aqueles que concebem e implementam soluções também exibem alguns mal-entendidos interessantes, relativamente aos SPCP. Primeiramente, destaca-se o domínio do conceito de sistema informático 
relativamente ao de sistema de informação, o que conduz à predominância de soluções de carácter geral. Estas soluções são supostamente aplicáveis a todos os tipos de organização industrial (SAP, 1994), e são integradas através de uma forte componente tecnológica, do tipo package parametrizável. Como tal impõem à organização a sua disciplina de funcionamento.

Em segundo lugar, estas soluções enquadram-se naquilo que já foi definido por Michael Hammer como fazer uma auto-estrada pavimentando caminhos de bois (in Jih \& Owings, 1995), privilegiando uma abordagem reducionista que almeja o 'encaixe' da solução na estrutura e nos processos informacionais existentes, na maior parte das vezes, já desadequados.

Terceiro, não reconhecem explicitamente a predominância da natureza social dos SPCP associados à maior parte dos sistemas de produção em lotes, quer na vertente de planeamento e controle, quer na vertente de sistema de informação. Como resultado, obtêm-se abordagens extremamente mecanicistas e complexas cuja filosofia enfatiza o controle e, mesmo, o 'controle do controle', preterindo a concepção de soluções inovadoras que simplifiquem e eliminem os problemas.

Finalmente, o interesse económico dos vendedores de soluções informáticas compromete a independência da sua análise, enquanto que o condicionamento proporcionado pela experiência, treino, formação e compromissos dos consultores poderá também promover abordagens autolimitadoras (Vilas-Boas da Silva, 1995) ao desenvolvimento de soluções com uma base mais rica e pluralista.

\section{Diagnóstico das necessidades para o contexto analítico de posicionamento dos SPCP}

No seguimento do que tem vindo a expor-se, pretende-se que o contexto analítico para posicionamento da actividade de planeamento e controle da produção no seio da organização goze de determinadas características que se passam a enumerar:

i) Holístico, porque a análise pretende endereçar um vasto número de subsistemas, como sejam os psicológicos e sociais, objectivos múltiplos e valores estruturais, técnicos e de gestão. As principais perspectivas da abordagem são: a) a contribuição para a organização como um todo (Buttery, 1989:319-20; Patton, 1987: 17); b) o tratamento de sistemas sociais e humanos diferentemente dos técnicos (Lewis, 1989: 254-56), e não ser reducionista (Tomlinson, 1989: 613). 
ii) Estratégico, porque os aspectos mencionados deverão ser reunidos e abordados tendo em atenção considerações de sensibilidades relevantes da temática estratégia para o negócio, nos seguintes aspectos: fixação de objectivos, escolha do rumo, desenvolvimento de planos, afectação de recursos, definição da acção e contribuição para a vantagem competitiva da organização (Hayes \& Wheelwright, 1984: 27).

iii) Pluralístico, não-tendencioso, descomprometido, completo e fiável (Buttery, 1989: 321), porque este contexto deverá posicionar os SPCP no seio da organização através de uma perspectiva de referenciação cruzada e triangulação do conhecimento proveniente de origens múltiplas e de paradigmas concorrentes (Patton, 1987: 60; Checkland, 1989: 40; Yin, 1994: 92; Robson, 1993: 383). A título de exemplo, citam-se, diferentes escolas da Teoria das Organizações, e da Gestão Estratégica, diferentes áreas funcionais (e.g. Operações $e$ Sistemas de Informação) $e$ paradigmas de implementação de SPCP diversos (Material Requirements Planning e Just-in-Time).

iv) Estruturado, porque o contexto a definir deverá exibir uma forma distinta, facultada por uma ordem interna coerente que permita a estruturação do problema, i.e., o processo pelo qual as exigências e necessidades, inicialmente apresentadas, se adequam a uma investigação detalhada, definindo-se assim o problema (Pidd, 1988; Lehaney \& Vinten, 1994).

v) Analítico, pois em paralelo com a preocupação holística, o contexto deverá proporcionar a possibilidade de aprofundamento, detalhe e discussão dos determinantes encontrados para os SPCP, de modo a extrair e sistematizar a riqueza do 'caos' inicial, por forma a que se possam definir actividades que constituam unidades razoáveis de investigação (Pidd, 1988).

vi) Não-determinístico, pois o impacto da introdução de sistemas de informação é dependente de opções e juízos de valor dos humanos durante o processo de desenvolvimento e implementação, sendo raramente explicado pela tecnologia per se. Os sistemas de informação devem então ser conceptualizados como sistemas sociais, pelo que a complexidade da sua função organizacional é melhor investigada por metodologias das ciências sociais (Symons \& Walsham, 1989a: 405).

vii) Contingencial, pois estando a desenvolver-se uma abordagem sistémica e estratégica em sistemas abertos cuja natureza social é relevante, terão necessariamente que se considerar, quer as transacções com a envolvente externa, quer as influências provenientes do contexto exterior. 


\section{Metodologia}

Este artigo reporta algumas conclusões a que se tem vindo a chegar num trabalho de investigação exploratório, cujo objectivo final é a definição de políticas orientadoras da selecção ou concepção e implementação de sistemas de planeamento e controle da produção. $O$ trabalho procura uma nova abordagem qualitativa do problema, com vista a endereçar uma questão relevante (Robson, 1993: 42): quais são os determinantes dos SPCP?

Finalmente, irá ser sugerido um conjunto de proposições, com base numa pesquisa bibliográfica alargada, envolvendo diversas áreas de conhecimento. Estas proposições exprimem a potencial influência dos determinantes achados para os SPCP na definição das políticas respectivas.

Sempre que possível, foram tomadas em consideração teorias rivais para os fenómenos em análise (Lehaney, 1989: 178), com vista, quer à criação de um contexto de abordagem mais rico, quer ao melhoramento da validade da construção em causa (Yin, 1994: 33).

$\mathrm{O}$ artigo está estruturado em quatro secções principais: introdução, desenvolvimento dos contextos descritivo $e$ analítico, análise do posicionamento dos SPCP no contexto analítico desenvolvido e conclusões.

\section{DESENVOLVIMENTO DOS CONTEXTOS DESCRITIVO E ANALÍTICO}

Na Figura $I$ representou-se o contexto descritivo do problema introduzido onde se identificaram duas grandes direcções de integração dos sistemas de planeamento e controle da produção no seio da organização: vertical e horizontal. $\mathrm{O}$ sucesso ou falha dos SPCP estão condicionados pelo nível da sua adequação a este contexto e, como tal, um sistema de avaliação do desempenho de SPCP deverá tomar em consideração estas dimensões.

A integração horizontal preocupa-se com a forma como a organização se posiciona na cadeia de valor acrescentado (Porter, 1985: 33-61), com o controle do fluxo físico de materiais durante o processo de transformação e com a contribuição do SPCP para o posicionamento do processo na cadeia logística e, consequentemente, para a criação de vantagem competitiva, segundo esta dimensão de análise. Esta dimensão não irá ser abordada neste artigo.

A integração vertical, além do papel desempenhado no enquadramento da dimensão horizontal, preocupa-se com a forma como é realizada a ligação dos SPCP à envolvente externa do negócio. Surgem aqui dois elementos 
cruciais: a estratégia e a estrutura dả organização. A sua articulação, bem como a ligação aos SPCP irão ser endereçadas no desenvolvimento do contexto analítico que se irá passar a detalhar de uma forma progressiva, i.e., passo-a-passo.

\section{Envolvente, estratégia, estrutura e tomada de decisão}

O debate na Teoria das Organizações tem-se preocupado com os aspectos determinantes da estrutura (Robbins, 1990: 24). As primeiras teorias relativas à estruturação das organizações ignoravam a envolvente externa, o tipo de organização e a especificidade das partes investigadas, promovendo generalizações e extrapolações, por vezes dúbias. Foram igualmente desprezadas as relações entre a estrutura e o modo de funcionamento da organização (Mintzberg, 1979: 13). De acordo com Robbins (1990: 39), o trabalho de Barnard foi um dos primeiros a considerar as organizações como sistemas e a desafiar a perspectiva de que a autoridade se afirmava no sentido descendente da hierarquia. Robbins (1990: 180) afirma ainda que o trabalho de Woodward nega a existência de princípios universais de gestão e organização, representando uma transição de uma perspectiva de princípios para uma teoria contingencial das organizações. Em apoio desta ideia, Hatch (1997: 161) afirma que os teóricos clássicos concebiam as relações que formam a estrutura social da organização como estáticas e rotinizadas. Consequentemente, a mudança somente ocorria quando a gestão decidia reconceber a organização. Finalmente, Woodward (1994: 74-7) detecta dois grupos de organizações: aquelas em que a formalização das organizações aparecia de forma imperceptível e gradual a partir da organização informal e as outras, em que era concienciosamente planeada. Woddward conclui que o planeamento consciencioso produz melhores resultados em determinados tipos de indústria do que em outros.

A abordagem contingencial tem sido a mais divulgada das perspectivas da relação envolvente-estrutura. A Teoria Contingencial especifica a envolvente como um dos determinantes da estrutura, tendo começado com a Teoria Sócio-Técnica que combina a ênfase na tecnologia com a atenção às pessoas, da Escola das Relações Humanas (Jelinek, 1977). Os outros determinantes eram então, a estratégia, a dimensão, a tecnologia, a própria estrutura existente e o poder, como se representa graficamente na Figura 2. Enquanto que Robbins (1990: 24) exclui o poder por considerar que a estrutura seleccionada conduz à maximização do con-trole, Mintzberg (1979: 221) inclui-o. 
Fig. 2

DESENVOLVIMENTO DO CONTEXTO ANALÍTICO: PASSO 1

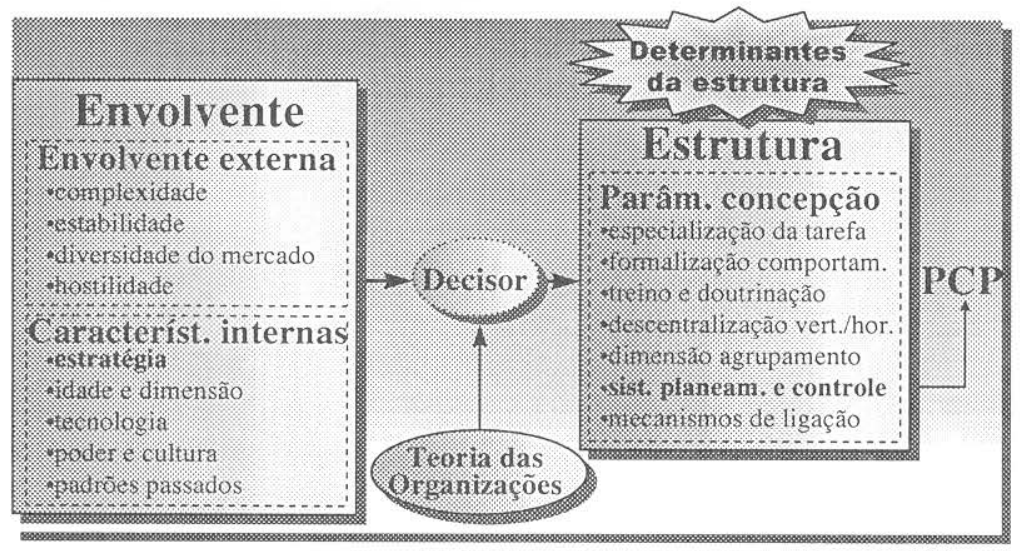

$\mathrm{Na}$ abordagem aqui delineada, a envolvente foi conceptualizada como a totalidade de factores físicos e sociais, quer interna, quer externamente à fronteira da organização que influenciam directamente o comportamento dos seus decisores (Duncan, 1972). Na Figura 2 a envolvente interna foi denominada por características internas.

\section{Influência da envolvente externa}

Hatch (1997: 64-75) divide a envolvente exterior em três categorias: i) a rede inter-organizacional que consiste em fornecedores, clientes, concorrentes, sindicatos, agentes reguladores e interesses especiais; ii) a envolvente geral, constituída por forças sociais, culturais, legais, políticas, económicas, tecnológicas e físicas que se manifestam na rede; iii) $a$ envolvente internacional e global que inclui aspectos que ultrapassam as fronteiras nacionais, ou que estão organizados numa escala global.

Duncan (1972) classifica a incerteza da envolvente face a duas dimensões: complexidade e estabilidade. Mintzberg (1979: 268-70) acrescenta mais duas dimensões à envolvente externa: a diversidade do mercado e a hostilidade. Contudo, considera que se deveria assumir a uniformidade do mercado, como hipótese de trabalho, a fim de se tornarem os problemas manipuláveis. Finalmente, Duncan (1972) e Hatch (1997: 89) entendem a incerteza como sendo função das percepções dos membros da organização e, portanto, não se constituindo como uma característica constante. 
Mintzberg (1979: 275, 286) e Robbins (1990: 230-32) sumariam a relação estruturalenvolvente externa, como se segue: i) envolventes estáveis e complexas originam organizações descentralizadas e burocráticas que utilizam a standardização das competências dos recursos como mecanismo de co-ordenação do trabalho; ii) envolventes dinâmicas e complexas requerem estruturas descentralizadas e orgânicas baseadas no mecanismo de mútuo ajustamento; iii) envolventes estáveis e simples geram organizações centralizadas e burocráticas que usam o mecanismo de estandardização do trabalho; e, iv) envolventes dinâmicas e simples dão origem a estruturas orgânicas e centralizadas, apoiadas no mecanismo de supervisão directa. Duncan (1972) considera que a dimensão estabilidade é o contribuinte mais importante para a incerteza do que a complexidade. Finalmente, Mintzberg (1979: 269) associa a hostilidade da envolvente com imprevisibilidade, argumentando que as envolventes hostis requerem reacções rápidas por parte da organização. Este autor considera ainda que a diversidade dos mercados variando entre mercados diversificados e integrados - afecta a variedade do trabalho em carteira.

Uma breve pesquisa detectou a envolvente externa, sendo correntemente caracterizada por uma economia de sociedade de informação, em que os recursos naturais e a mão-de-obra barata foram substituídos pelo conhecimento e pela comunicação (Jih \& Owings, 1995). Os mercados são descritos como mais turbulentos, mais difíceis de prever, mais saturados e mais competitivos (Mertins et al, 1994). Esta economia de sociedade de informação originou uma tendência de globalização que diminuiu a importância dos mercados nacionais e facilitou novas políticas de comércio que modificaram os padrões da competição internacional (Porter, 1986). A globalização do mercado tem ainda sido relacionada com as elevadas taxas de crescimento das tecnologias de informação (TI),o que permite um melhor controle à distância e através da dimensão tempo, bem como um maior envolvimento interno nas organizações (Edwards \& Peppard, 1994). Estes argumentos poderão explicar as razões por que o crescimento das despesas nas TI decaplicou para os PCs e duplicou para as mainframes, entre 1983 e 1993 (Jih \& Owings, 1995).

\section{Influência das características internas}

De acordo com Hum \& Sim (1996), a indústria tradicional tinha como objectivo minimizar custos através da utilização de recursos baratos, nomeadamente a mão-de-obra. Na década de 60 , a indústria direccionou-se para estratégias de larga-escala, usando equipamentos especializados para 
produzir grandes volumes a baixo custo unitário de produção. Em meados dos anos 70, a melhoria da produtividade focou-se em produtos e competências específicas. Reduziu-se a complexidade, conseguindo-se assim melhor produtividade e custos mais baixos do que a indústria 'generalista' possuía. Contudo, a fábrica-foco impunha restrições à variedade dos produtos. Esta limitação na competitividade e crescimento empurrou as empresas Japonesas de vanguarda em direcção à flexifactory, a fábrica flexível em que o compromisso entre escala e variedade deixou de existir (Mair, 1994). Nos anos 80 e 90 a exigência de variedade tem levado os competidores globais a introduzirem novos produtos e maior variedade a taxas elevadas e custos reduzidos (Jih \& Owings, 1995; Sweeney \& Szwejczewski, 1995), levando ao paradigma competitivo actual: time-based competition. Esta é uma estratégia orientada para a resposta ao cliente e ciclos de vida dos produtos curtos, em paralelo com qualidade competitiva, custo e produtividade (Ayers, 1995). É esta a essência dos world class manufacturers (Ward et al, 1993; Burcher \& Stevens, 1996).

\section{O efeito da idade e da dimensão da organização}

A formalização do comportamento das organizações tende a aumentar com a idade, o que origina um impacto positivo no dimensionamento dos agrupamentos, i.e., quantas posições por agrupamento $\mathrm{e}$ quantos agrupamentos de nível inferior se juntam num de nível superior. Para além disto, a estrutura exibe sinais que reflectem a data da fundação da organização (Mintzberg, 1979: 227-28). Khandwalla (1977: 301-02) sugeriu que os objectivos da organização se tornavam mais flexíveis, ao passo que a estrutura social mais inflexível com a idade. Defendeu ainda que as organizações mais velhas tendem a procurar envolventes exteriores mais estáveis, a ser menos ambiciosas e mais conservadoras nas suas políticas e filosofias.

O efeito de aumento da dimensão, mantendo constante o sistema técnico e a envolvente externa, pode resumir-se em maior divisão do trabalho, maior diferenciação entre agrupamentos e mais níveis hierárquicos (Khandwalla, 1977: 295-97; Mintzberg, 1979: 234; Robbins, 1990: 152-62). Estes aspectos implicam menor necessidade de co-ordenação intra-agrupamento e maior coordenação inter-agrupamento. Refira-se, contudo que Robbins (1990: 15456) detectou contradições na avaliação da importância do impacto da dimensão. Enquanto alguns investigadores salientam a dimensão como a mais importante condição afectando a estrutura da organização, outros 
referem que, nem a complexidade, nem a formalização da organização podem ser implicadas a partir da sua dimensão.

\section{O efeito da tecnologia}

O conceito de tecnologia é definido por Hatch (1997: 128) como: i) os objectos fisicos ou artefactos, incluindo produtos, ferramentas e equipamentos usados na produção; ii) as actividades ou processos que compreendem ós métodos de produção; iii) o conhecimento necessário à aplicação dos equipamentos, ferramentas e métodos, com vista à produção de um output específico. Em convergência com esta definição, Mintzberg (1979: 250-51) distingue entre complexidade do sistema técnico e da tecnologia: um sistema técnico complexo pode ser simples de operar, e.g., o automóvel, enquanto que um sistema técnico simples pode requerer tecnologia muito complexa, e.g., o bisturi de um cirurgião. Considera ainda a regulação, a sofisticação, a taxa de mudança e a divisibilidade como as principais dimensões dos sistemas técnicos. Sistemas técnicos com maiores necessidades de regulação requerem que o trabalho do operador seja mais formalizado e um núcleo operacional mais burocrático. Sistemas técnicos mais sofisticados requerem um apoio de staff em maior quantidade e mais especializado, bem como maior uso de mecanismos de ligação. Por outro lado, a automação do núcleo operacional transforma uma estrutura administrativa burocrática numa estrutura orgânica (Mintzberg, 1979: 261).

Joan Woodward foi a primeira investigadora a isolar e avaliar as variáveis técnicas de dependência da organização (Jelinek, 1977), baseada numa classificação das firmas com características técnicas em comum. Woodward (1994: 37-40) define três grandes grupos ao longo de uma escala de complexidade tecnológica crescente: i) produção unitária e em pequenos lotes; ii) produção em grandes lotes e em massa e, iii) processo. Woodward (1994: 50-51) apresenta como principal conclusão do seu projecto a existência de uma relação entre tecnologia e estrutura, nos seguintes elementos: extensão da linha de comando; abrangência da função do chefe executivo; rácios de managers para o total de pessoal, do staff administrativo para os operadores, da mão-de-obra directa para indirecta, de licenciados para não-licenciados empregados na supervisão da produção e, o número de níveis de gestão nos departamentos de produção. Woodward (1994: 40) também detecta procedimentos de planeament $\delta$ e controle da produção bem desenvolvidos em firmas produzindo em lotes, onde existia um certo grau de incerteza associado à previsão de resultados. 
A tipologia de Thompson para a tecnologia introduz uma segunda dimensão conceptual, o nível de estandardização de inputs e outputs, de que resulta a classificação: i) tecnologias ligadas, caracterizadas por uma interdependência sequencial; ii) tecnologias mediadoras, caracterizadas por um interdependência compartilhada; iii) tecnologias intensivas, caracterizadas por uma interdependência recíproca (Hatch, 1997: 138; Robbins, 1990: 188-91).

Perrow considera a variabilidade da tarefa - número de excepções relativamente aos procedimentos standard na aplicação de uma dada tecnologia - e a analisabilidade da tarefa - até que ponto a excepção é encontrada - como dimensões da tecnologia (Hatch, 1997: 140-42; Robbins, 1990: 182-85). Com base nestas dimensões, Hatch constrói uma matriz $2 \times 2$ que proporciona uma classificação de que se salientam os dois extremos: i) tecnologias de rotina, caracterizadas por pequena variabilidade e grande analisabilidade, e.g., linha de montagem de automóveis, e ii) tecnologias de não-rotina, exibindo alta variabilidade e pequena analisabilidade, e.g., planeamento estratégico, actividades de investigação, etc. Robbins (1990: 199-201) conclui que, quanto mais a tecnologia for do tipo rotina, mais altamente estruturada deve ser a organização, mais standardizada será a coordenação e o controle e, tanto maior formalização e centralização exibirão as estruturas organizacionais. Tecnologias do tipo não-rotina necessitariam de uma estrutura flexível, grande interacção entre os membros da organização, pequeno grau de formalização e descentralização.

Hatch (1997: 137) criticou as conclusões de Woodward de que os níveis de desempenho mais elevados se encontravam quando se combinavam tecnologias de produção em massa com formas mecanísticas de organização e quando se combinavam tecnologias de processo ou de produção de pequenos lotes com formas orgânicas de organização, argumentando que o estudo se reportava a PMEs e ignorava organizações não industriais. Podemos acrescentar, a esta crítica, a limitação dos casos estudados por Woodward, a uma região de Inglaterra. Contudo, Mintzberg (1979: 261-4) enunciou três hipóteses solidárias com a afirmação em causa, com uma base completamente diferente. Por outro lado, também a abordagem de Perrow (in Robbins, 1990: 185) suporta a afirmação, o que resulta na replicação literal do fenómeno e, portanto, numa aceitável generalização analítica (Yin, 1994: 31,108 ).

As novas tecnologias (NT) - tornadas possíveis pela aplicação dos computadores, micro-electrónica e telecomunicações - apresentam características de desempenho não-determinística, sendo difíceis de controlar, criando falhas incompreensíveis e inesperadas e exibindo aleatoriamente padrões que não se repetem. As NT promovem a mudança 
organizacional, encorajam e suportam a inovação e criam preocupações de melhoramento da produtividade (Hatch, 1997: 154-6). Por outro lado, a revolução das TI estabelece uma nova envolvente para a organização em que as interligações entre gestores, diferentes níveis de gestão e em diferentes funções da organização, bem como as relações entre as diferentes organizações, se modificam substancialmente. Muitas organizações reagem aumentando a complexidade organizacional e dos sistemas de informação e de controle, a fim de evitar o colapso e para lidar com uma variedade crescente e capacidades dos recursos humanos que não se adaptaram (Robb, 1989:248). Este movimento tem sido orientado para uma amplificação da complexidade, numa espiral aberta (Stacey, 1995: 62).

\section{O efeito do poder e da cultura}

Robbins (1990: 438) e Siehl \& Martin (1984: 227) definem cultura organizacional como um sistema de valores partilhados, baseado em padrões de crenças, símbolos, rituais, mitos e práticas que progridem através do tempo e mantêm a organização unida. Robbins (1990: 443) considera a cultura como um substituto da formalização, porque pode criar previsibilidade, ordem e consistência sem a necessidade de documentação escrita.

Mintzberg (1979: 288-95) considera três factores de dependência do poder - propriedade, necessidades pessoais dos membros e moda -, analisando a sua influência na estrutura organizagional. $O$ exercício do direito de propriedade, traduzido por necessidades de controle externo, e.g., escolha da administração e a imposição de normas claras, origina estruturas mais centralizadas e formalizadas. Por outro lado, as necessidades de poder dos membros também contribuem para uma maior centralização vertical e horizontal. Henry Ford tem sido citado como exemplo clássico desta atitude. Finalmente, as estruturas que seguem 'a moda do mês', propostas por consultores e publicações científicas, podem não ser igualmente adequadas para todas as organizações.

\section{A estrutura organizacional}

\section{Conceitos de estrutura e estruturacão}

Mintzberg (1979: 2) define estrutura da organização como o somatório das formas em que se divide e coordena o trabalho. Robbins (1990: 5-6) 
acrescenta a afectação de tarefas, a definição das relações de reporting e os padrões de interacção consequentes. Considera, ainda, como objecto da estruturação/concepção da organização, a construção e a mudança da estrutura organizacional, com vista à prossecução dos objectivos da organização.

Os cinco mecanismos de coordenação do trabalho, identificados por Mintzberg (1979: 3) que explicam o modo como as organizações coordenam - seu trabalho são: o mútuo ajustamento, a supervisão directa e a estandardização dos processos de trabalho, dos outputs e das competências.

\section{Dimensões ou áreas de decisão da estrutura organizacional}

Robbins (1990: 82) e Hatch (1997: 167-73) consideram a complexidade, a formalização e a centralização como as principais dimensões da estrutura organizacional. Mintzberg (1979: 67) utiliza uma semântica diferente (especialização da tarefa, formalização do comportamento, treino e doutrinação, agrupamento e dimensionamento de unidades estruturais e descentralização vertical e horizontal), acrescentando os sistemas de planeamento e controle e os mecanismos de ligação (Figura 2). Estes são as categorias de decisão que devem ser tidas em consideração na definição da estrutura da organização. Mintzberg (1979: 218) formula ainda a hipótese de configuração que estabelece que 'uma estruturação eficaz necessita de consistência interna entre as diversas categorias de decisão relativas ao desenho organizacional'.

\section{$\underline{\text { Modelação da organização }}$}

Tradicionalmente, as organizações têm sido descritas por organogramas representando a autoridade formal (Mintzberg, 1979: 36). Contudo, a perspectiva da organização como uma rede de fluxos regulados, representando-a como um sistema de processos sistemáticos e explicitamente controlados funcionando sem sobressaltos, permanece dominante na literatura dos sistemas de planeamento e controle, tal como o era para os teóricos clássicos. Estes fluxos são canais que transmitem informação de feedback para o topo da hierarquia e comandos e instruções do topo para a base, através dos níveis intermédios de gestão (Mintzberg, 1979: 37, 42-43). No entanto, as organizações funcionam de forma mais complexa, pois muita actividade toma lugar fora dos sistemas de autoridade formal e dos fluxos regulados. 
Até este ponto foram analisados os factores contingenciais (excepto os aspectos estratégicos e os padrões prosseguidos pela organização no passado) e introduziram-se os parâmetros associados à concepção da estrutura organizacional de uma forma isolada. Importa, pois, endereçar a relação estrutura-factores contingenciais, relativamente à qual se vão explorar duas perspectivas. Por um lado, Mintzberg (1979: 221), através da hipótese de congruência, e também Robbins (1990: 24), constatam a ocorrência de uma forte correlação entre ambos, não sendo, no entanto, possível estabelecer uma relação de causalidade. É ainda referido que é mais popular e viável mudar a estrutura (variável dependente), a fim de garantir a harmonia desta relação. Contudo, existem exemplos de grandes organizações que conseguem controlar a sua envolvente (variável 'independente') através, quer do poder que possuem sobre os seus componentes (Robbins, 1990: 229), quer da utilização de ferramentas como o marketing. Em resumo, nesta perspectiva, a organização é conceptualizada como um conjunto de factores tecnológicos, culturais e estruturas física e social - que interagem, se interpenetram e emergem organicamente no contexto de uma envolvente, de acordo com a Figura 2 (Hatch, 1997: 15; Peters \& Waterman, 1995: 4-5, 10).

Por outro lado, desde o ano de 1962 em que Alfred Chandler escreveu Strategy and Structure, a estrutura organizacional é vista como o output optimizado, racional, intencional e realizado do exercício de planeamento e análise estratégica (Figura 3). A realidade das organizações está posicionada algures entre estas duas abordagens rivais da relação estrutura-estratégia-envolvente.

\section{Caracterização das estruturas organizacionais do passado}

As velhas estruturas de poder, sistemas de controle e técnicas motivacionais são, muitas vezes, inapropriados para os novos tipos de economia (Stanley, 1989: 428), porque são burocráticas, focadas para dentro, incapazes de resposta, improdutivas e opressivas (Jih \& Owings, 1995). Edwards \& Peppard (1994) defendem que a maior parte das organizações estão ainda organizadas em torno de conceitos de divisão do trabalho, especialização funcional, autoridade do chefe, uma estrutura hierárquica que suporta um controle e uma coordenação centralizados (apesar destas características originarem objectivos incompatíveis e inconsistentes), em torno de uma competição inter-funcional maléfica. 


\section{Caracterização das estruturas organizacionais alvo}

Actualmente, desejam-se organizações ligadas em rede, inovadoras e que 'aprendam', de modo a poder retirar-se a máxima vantagem da contribuição dos indivíduos, sendo esta inspirada por uma referência comum baseada nos objectivos organizacionais. Estas organizações deverão ser capazes de facultar informação 'exacta', atempada e compreensiva, às pessoas que possam acrescentar valor ao funcionamento do negócio, inserido num contexto organizacional optimizado (Stanley, 1989: 428).

Podem então sumariar-se as características destas organizações como sendo: dinâmicas; rápidas a responder, com poucos níveis intermédios de gestão; orientadas para o trabalho em grupo (Ayers, 1995); baseadas no compromisso em vez do controle (Goodridge, 1988); promovendo o empowerment dos níveis mais baixos, enquanto que os managers devem actuar mais como consultores, intervindo segundo uma perspectiva pluridisciplinar e promovendo uma estrutura mais horizontal, intimamente relacionada com os processos de gestão necessários à satisfação das necessidades dos clientes (Edwards \& Peppard, 1994) e, por último, fortemente interligada em rede com clientes e fornecedores (Jih \& Owings, 1995). Por outro lado, o processo de avaliação deverá ser mais baseado no desempenho do grupo do que no mérito individual, focado nos resultados em lugar de o ser na actividade, baseado em critérios múltiplos não-financeiros, procurando simultaneamente satisfazer exigências de qualidade e produtividade, orientado para o exterior e com foco nos produtos e serviços requeridos pelos clientes (Edwards \& Peppard, 1994; Kaplan, 1984, 1986; Kaplan \& Norton, 1992, 1993, 1996).

Estes são alguns dos aspectos cruciais com vista ao alcance da mudança radical requerida nos anos 90 , a fim de melhorar a eficácia dos processoschave em 50 a $100 \%$, em vez das habituais taxas de melhoramento na ordem dos 5 a $10 \%$ em todos os processos (Fiedler et al, 1994).

\section{Estratégia e processo estratégico}

A Figura 3 enfatiza e isola o factor contingencial estratégia que, pela sua importância, foi tratado de forma individual. As escolas de estratégia mais importantes são prescritivas na orientação, tratando a formação da estratégia como um processo de projecto conceptual, planeamento formal e análise do posicionamento do negócio. 
Fig. 3

\section{DESENVOLVIMENTO DO CONTEXTO ANALÍTICO: PASSO 2}

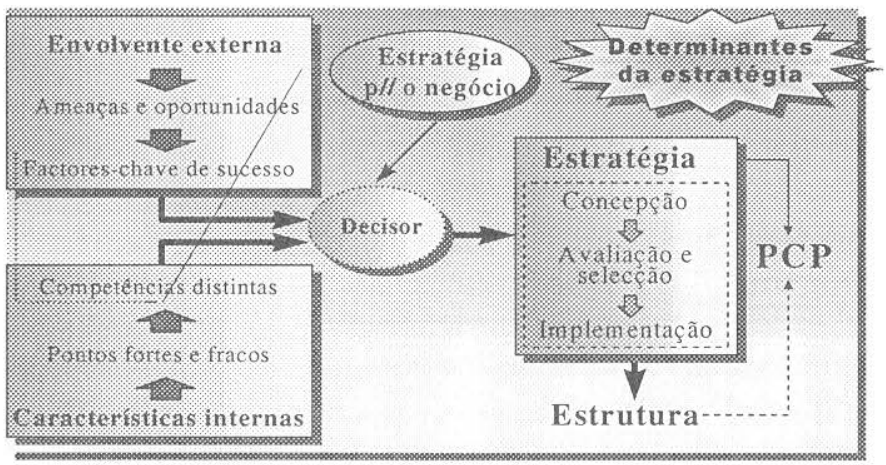

Mintzberg (1990) considera que elas pro-movem o pensamento de modo independente da aç̧ão, ignorando o conhecimento vindo do processo de tentativa e experimentação que ele, de forma geral, denominou estratégia emergente (Mintzberg, 1987; Ansoff, 1991). Ele também discorda de Chandler e Andrews, de que a estrutura deve seguir a estratégia e ser determinada por ela, argumentando que cada uma delas sempre segue a outra, excepto quando se movem juntas, no caso da organização saltar para um nova posição competitiva. Finalmente, Mintzberg (1985) considera que estratégias deliberadas e emergentes formam os dois pólos de um continuum ao longo do qual se posicionam as estratégias reais.

\section{O modelo da design school}

Nesta abordagem (Johnson \& Scholes, 1997: 43), a análise estratégica tem como objectivo o entendimento da posição estratégica da organização, a escolha estratégica, a formulação, avaliação e selecção de cursos de acção possíveis e a implementação estratégica, o planeamento e a gestão do processo de mudança organizacional (Figura 3).

A abordagem fit da design school identifica ameaças e oportunidades na envolvente competitiva (Figura 3), desenvolvendo os recursos necessários para lidar com as mesmas. Por outro lado, a abordagem stretch cria perspectivas do futuro em que são desenvolvidas competências únicas para a organização, vista como um todo, que deverão proporcionar vantagem sobre a concorrência ou criar, quer novas oportunidades, quer novos mercados (Prahalad \& Hamel, 1990; Edwards \& Peppard, 1994; Johnson \& Scholes, 
1997: 25). Esta perspectiva representa uma forma de ultrapassar as estratégias genéricas, correntemente prosseguidas, e de expandir o conteúdo tradicional da estratégia.

\section{Prioridades competitivas}

A escolha das prioridades competitivas deve suportar a escolha da estratégia competitiva genérica para o negócio (Tunalv, 1992): diferenciação, foco, ou liderança de custos (Scholes, 1997: 251). A estratégia de marketing está implicitamente considerada na escolha das estratégias genéricas e das prioridades competitivas, pelo que não foi explicitada.

A qualidade, os custos, a fiabilidade da entrega, a flexibilidade, a concepção, o apoio técnico no pós-venda e a dimensão tempo são algumas das prioridades competitivas críticas necessárias, com vista à conquista de encomendas, num determinado mercado, para um dado período e para uma dada família de produtos (Hill, 1993: 64). Contudo, Prahalad \& Hamel (1990) consideram estes critérios apenas como atributos dos produtos-finais e no curto prazo. Defendem então que, para mercados globais, no longo termo, a competitividade derivava da capacidade de construir, de forma mais económica e mais rápida que os concorrentes, competências-base que produzem, de modo inesperado, produtos-base e produtos-finais. Por exemplo, as competências-base que a Honda desenvolveu na concepção e produção de motores tem-lhe permitido expandir o seu negócio através de uma gama alargada de produtos, tais como: motociclos, automóveis, geradores e máquinas agrícolas. A diferença entre as competências que promovem a distinção de um negócio e as competências-base é que os concorrentes se apercebem das primeiras e podem imitá-las, sendo, portanto, vulneráveis (Dawes, 1995). Por outro lado, as competências-base são poucas, únicas, são uma mistura de competências individuais, de recursos e de processos, resultando muito mais significativas que as competências individuais e sendo comercializáveis. Elas são essenciais à sobrevivência da organização, ao processo de análise e planeamento estratégico, à implementação da estratégia e ao desenvolvimento de produtos-base e de produtos-finais (Tampoe, 1994; Dawes, 1995).

\section{Estratégia de operações}

A estratégia de operações é a estratégia funcional que liga a estratégia do negócio à escolha dos SPCP (Figura 4) (Hayes \& Wheelwright, 1984: 29). 
As abordagens mais populares à formulação da estratégia de operações seguem a perspectiva fit da design school, sendo prescritivas, analíticas e racionais (Platts \& Gregory, 1990).

Estas perspectivas promovem a compatibilização, entre as competências e prioridades do sistema de fabrico e os critérios competitivos que os produtos e serviços da empresa devem satisfazer. Esta é a condição para o suporte da vantagem competitiva do negócio (Hayes \& Wheelwright, 1984: 40-41; Skinner, 1985: 41; Hill, 1993: 42-47, 55; Slack, 1991: 186-90; Platts \& Gregory, 1994: 4, 9; Miller, 1981).

Os SPCP fazem parte da categoria de decisão da estratégia de operações infra-estrutura e, as decisões que lhes digam respeito, devem ser consistentes com as restantes áreas de decisão (Hayes \& Wheelwright, 1984: 33), a saber: capacidade, instalações, tecnologia, integração vertical, força laboral, qualidade e organização (Hayes \& Wheelwright, 1984: 31; Vilas-Boas da Silva, 1994).

\section{Estratégia para os sistemas e tecnologias de informação (SITT)}

Considerou-se a estratégia para os SI/TI, representada na Figura 4, dado que os SPCP processam informação fazendo uso das tecnologias de informação (TI). Por outro lado, as taxas de inovação e mudança ocorridas na envolvente competitiva, relativas às $\mathrm{TI}$, não se podem ignorar, dada a importância das TI na estruturação da organização. Finalmente, a estratégia para os SI/TI engloba toda a tecnologia da organização e também a produtiva que é simultaneamente uma categoria de decisão da estratégia de operações. Deverá então ser introduzida uma preocupação relativa à consistência das decisões entre estas duas estratégias funcionais: operações e SI/TI.

Segundo Ward \& Griffiths (1996: 28-32) a estratégia para os SI/TI resulta de se: i) procurar compreender o potencial dos SI/TI, do ponto de vista estratégico do negócio; ii) considerar a informação como um recurso estratégico; iii) considerar a influência dos factores externos, a par com os internos; iv) orientar para a organização como um todo os investimentos em SI/TI; v) mudar a perspectiva dos SI/TI, de minimizar custos para adicionar valor e, vi) necessitar de envolver os gestores de topo. Peppard (1993: 27) acrescenta a elevada taxa de crescimento das despesas de investimento e manutenção, a transformação do horizonte temporal respectivo em longo prazo, o impacto na concepção e gestão da organização e o impacto nas interfaces organizacionais externas. A estratégia para os SI responde à questão: que é necessário? enquanto que a estratégia para as TI procura 
definir como é que as necessidades de aplicações podem ser implementadas (Peppard, 1993: 18).

As abordagens à estratégia para os SI/TI, popularizadas recentemente, seguem a design school (Ward \& Griffiths, 1996: 103, 112, 119, 252; Peppard, 1993: 18, 85, 91; Earl, 1989: 58, 71-72, 90, 121) e, quer a perspectiva fit, quer a strecht, têm sido consideradas em função do tipo de sistema de informação. O modelo de McFarlan tem sido utilizado para classificar os SI de acordo com a sua contribuição para o sucesso do negócio, em vez desta se focar, exclusivamente, nas tarefas necessárias. Assim resultou a seguinte tipologia: i) SI de suporte - caracterizados por pequeno impacto no presente e futuro, investimento médio e necessidade de atenção ocasional dos gestores sénior; ii) SI operacionais-chave - cruciais para a operação, mas fora do âmago do desenvolvimento estratégico; iii) SI de elevado potencial - os TI e SI planeados poderão ser críticos para a sobrevivência do negócio no futuro e, iv) SI estratégicos - SI críticos para o negócio e determinantes do futuro (Earl, 1989: 5-7; Ward \& Griffiths, 1996: 32, 275; Peppard, 1993: 94).

A estratégia para as TI tem como objecto o planeamento e exploração da infra-estrutura tecnológica de modo a suportar a estratégia do negócio, satisfazendo as necessidades da estratégia para os SI através da implementação das aplicações no portfolio, em alternativa ao desenvolvimento tecnológico reactivo tradicional (Ward \& Griffiths, 1996: 493; Earl, 1989: 115). Ward \& Griffiths (1996: 490) enumeram os seguintes elementos da infra-estrutura tecnológica: i) infra-estrutura fisica: hardware, software de sistema, sistemas de comunicações e redes, ferramentas de desenvolvimento como o CASE e RAP, software relativo às aplicações funcionais e software específico, como sejam aplicações de EDI e inteligência artificial; ii) arquitecturas: modelos da infra-estrutura física, bem como, de informação, processos e estrutura organizacional; iii) políticas: contratação, auditoria, segurança, nível de serviço capacidade, entre outras; iv) processos de gestão e serviços de apoio: planeamento e gestão das instalações, gestão de fornecedores, apoio técnico aos utilizadores e treino. Earl (1989: 113-15) salienta algumas lições provenientes da prática de aplicação das TI, como se segue: imposição de horizontes temporais de acordo com o ciclo de vida da tecnologia; implementações faseadas passo-apasso, mas rápidas; promoção de experiências piloto; satisfação das necessidades, da estrutura e do estilo organizacionais; melhoramento contínuo da arquitectura de TI; disponibilização de tempo de dedicação, por parte de gestores, especialistas e utilizadores e, finalmente, apoio da gestão de topo. 


\section{Padrões passados prosseguidos pela organização}

Mintzberg (1987) afirma que 'as estratégias são simultaneamente planos para o futuro e padrões do passado' querendo significar que, invariavelmente, as estratégias são consistentes com um padrão de comportamento passado. Sendo esse padrão fisicamente representado pela estrutura da organização, tem-se uma situação de iteractividade entre estrutura e estratégia, como já foi referido e agora se representa na Figura 4.

Fig. 4

\section{CONTEXTO ANALÍTICO PARA POSICIONAMENTO DOS SPCP}

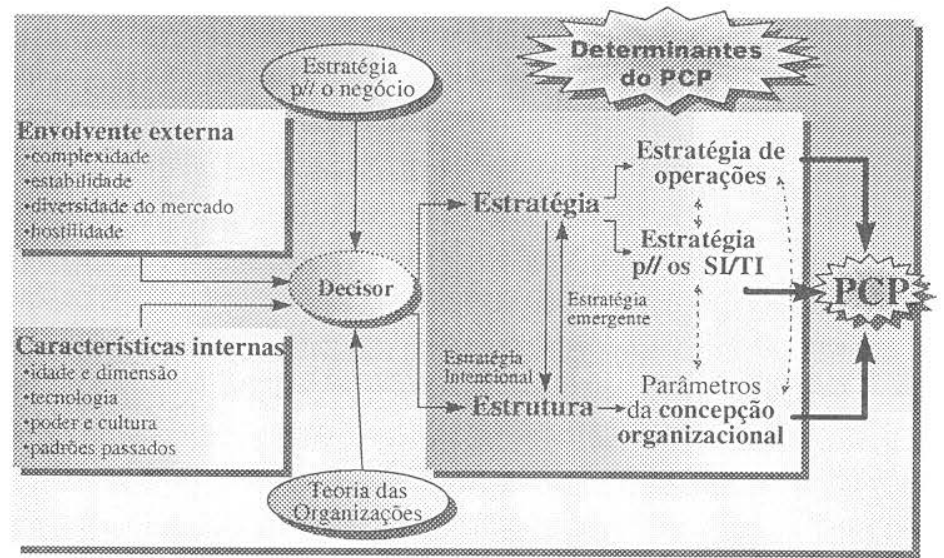

A Figura 4 representa esquematicamente o contexto analítico a que se chegou, pela inclusão daqueles que foram sendo identificados como os determinantes dos sistemas de planeamento e controle da produção, no âmbito da abordagem desenvolvida.

\section{ANÁLISE DO POSICIONAMENTO DOS SPCP NO CONTEXTO ANALÍTICO DESENVOLVIDO}

Nesta secção vai resumir-se a pesquisa efectuada em proposições que reflectem os determinantes achados para os SPCP e que condicionam o seu desempenho. Consequentemente, as políticas para a sua selecção ou concepção e implementação deverão ser coerentes com estes determinantes. 
A abordagem contingencial significa que a estrutura se deve adaptar a mudanças nas variáveis independentes (Robbins, 1990: 24), sejam estas devidas a uma estratégia deliberada - realizada de acordo com a intenção ou a uma estratégia emergente - padrões realizados apesar ou na ausência de intenções (Mintzberg, 1985). Proposição: «As políticas para os SPCP devem considerar a satisfação das exigências colocadas pelos determinantes da estrutura». Contudo, embora os factores contingenciais imponham restrições à organização, coloquem exigências incertas de adaptação como preço da sobrevivência e criem uma relação de dependência (Hatch, 1997: 63), o imperativo da envolvente externa tem sido objecto de discussão. Isto porque algumas grandes empresas conseguem criar uma envolvente que reflecte a estrutura de que é vista (Robbins, 1990: 223), o que não sendo normal, é possível.

A envolvente exterior das organizações está a mudar de forma irreconhecível (Stanley, 1989: 428) e os sistemas e tecnologias de informação são parte integrante e relevante do processo (Lockett, 1989: 447). O paradigma dos anos 60 não reconhece os processos organizacionais, ou permite que estes sejam sobrepostos pela estrutura funcional tradicional, resultando em duplicação de tarefas e nas respectivas ineficiências (Edwards \& Peppard, 1994). Por outro lado, a velocidade é apontada como a principal pressão dos anos 90 e a dimensão tempo como a próxima fonte de vantagem competitiva (Hum \& Sim, 1996). Proposicão: «As políticas para os SPCP deverão preocupar-se com a sua contribuição para melhorar a capacidade de resposta organizacional, quer na organização interna, quer pela melhor articulação externa na cadeia comercial, com base em processos horizontais que adicionem valor para o cliente e através da aplicação inovadora das TI».

Hatch (1997: 89), baseada no trabalho de Duncan (1972), relaciona o nível de incerteza da envolvente externa com as expectativas de necessidade de informação, do seguinte modo: envolventes estáveis e complexas geram uma incerteza moderada e um excesso de informação; envolventes dinâmicas $e$ complexas são caracterizadas por elevada incerteza e requisitos de informação desconhecidos; envolventes estáveis $e$ simples resultam em pequena incerteza, necessidades de informação conhecidas e disponibilidade de informação; e, envolventes dinâmicas $e$ simples são caracterizadas por incerteza moderada e constante necessidade de informação. Para além disto, a diversidade do mercado e a hostilidade da envolvente aumentam a incerteza (Mintzberg, 1979: 269). Proposição: «As políticas para os SPCP devem considerar a sua contribuição para a redução da incerteza apreendida, face ao tipo de informação disponível e ao tipo de envolvente». 
Mintzberg (1979: 227) sugere que o aumento de dimensão da organização resulta em: i) comportamento mais formalizado e maior utilização de sistemas de planeamento e controle que conduzem a estruturas mais burocráticas e ii) descentralização. No entanto, existe uma controvérsia associada ao efeito da dimensão, originando diferentes conclusões, em função, quer do tipo de amostra ou caso, quer do tipo de metodologia (Robbins, 1990: 154-6). Por outro lado, Robbins (1990: 167-70) salienta a especificidade dos problemas e soluções associados às PMEs. Proposição: «As políticas para os SPCP devem ter em atenção o ponto-crítico da dimensão da organização e, quando a dimensão aumenta, a contribuição dos mecanismos de formalização para o controle da descentralização».

A tipologia de Woodward revela uma ligação da "performance" à estrutura, mas apenas quando se consideram os tipos de tecnologia usados (Hatch, 1997: 135). Por exemplo, as maiores dificuldades em exercer um controle eficaz ocorriam na produção unitária, em que era quase impossível prever os resultados do trabalho (Woodward, 1994: 40). Por outro lado, Robbins (1990: 199-201) refere que, se a formalização for elevada, a tecnologia de rotina pode ser considerada verticalmente descentralizada, no que respeita à concentração da autoridade formal. Proposição: «As políticas para os SPCP devem considerar o tipo de tecnologia, as dimensões do sistemas técnico, a estandardização dos I/O e a 'rotinação' da tecnologia».

A concentração do poder no topo da pirâmide hierárquica gera procedimentos pessoais mais restritivos, processos de trabalho mais estandardizados, comunicação mais formal, uma função de reporting mais regulada, mais planeamento e menor capacidade de adaptação (Mintzberg, 1979: 291). Robbins (1990: 444) sugere que uma cultura mais forte implica uma menor necessidade de regras, regulamentos e procedimentos formais de orientação do comportamento, isto é, de formalização. Proposição: «As políticas para os SPCP devem considerar as necessidades de poder dos detentores do capital e dos restantes membros da organização, a eficácia da cultura organizacional e as pressões das práticas mais populares».

Tendo-se verificado a indispensabilidade de uma estratégia intencional que faculte uma orientação para a evolução da organização e guie o processo de mudança, também se concluiu sobre a evidência da influência retroactiva do processo de implementação, através das estratégias emergentes. Ambas as estratégias - intencionais e emergentes - são influenciadas pela estrutura existente, i.e., os padrões prosseguidos pela organização no passado (Mintzberg, 1987). Proposição: «As políticas para os SPCP devem equilibrar as exigências da abordagem estratégica escolhida com os padrões prosseguidos pela organização, de acordo com as necessidades 
de rotura ou continuidade, estabelecidas pelos critérios competitivos e pelas competências-base».

O tipo de apoio facultado pela estratégia de operações à estratégia da organização é definido como internamente neutro, externamente neutro, internamente activo, ou externamente activo (Hayes \& Wheelwright, 1984:396). Proposição: «As políticas para os SPCP devem ser solidárias com: i) o suporte facultado pela estratégia de operações à estratégia da organização; ii) a consistência entre os SPCP e as restantes categorias de decisão da estratégia de operações e iii) a consistência entre a estratégia de operações e as restantes estratégias funcionais».

As aplicações de SI de elevado potencial e estratégicas suportam perspectivas do futuro em que se devem criar competências únicas que facultem vantagem competitiva sobre a concorrência, o que está de acordo com a perspectiva stretch. Por outro lado, os SI operacionais e de suporte, em que o objectivo mais importante é evitar desvantagem competitiva, pelo melhoramento da eficiência através de soluções de baixo custo no longo termo (Ward \& Griffiths, 1996: 279-80), estão mais próximas da perspectiva fit da design school. Proposição: «As políticas para os SPCP devem ter em atenção o posicionamento dos SPCP no portfolio das aplicações, quer em termos das expectativas de suporte competitivo do negócio - avaliação do desempenho, quer em termos das exigências de avaliação financeira, relativamente ao investimento, aos gastos de operação e de manutenção».

A utilização de forma proactiva das tecnologias de informação cria novas oportunidades para o negócio (Peppard, 1993 :16). Proposição: «As políticas para os SPCP devem ter em consideração: i) a consistência entre as estratégias para as tecnologias de informação e as para os sistemas de informação; ii) a consistência entre as estratégias para as TI e de operações; iii) a consistência entre os elementos da infra-estrutura tecnológica, relativamente aos seus planeamento, gestão e operação e, iv) as sinergias entre as diferentes tecnologias».

A maior parte dos gestores favorece a comunicação informal, passando grande parte do seu tempo comunicando fora do sistema formal. Os Management Information Systems (MIS) formais ignoram completamente a informação soft, intangível e especulativa, tendo como consequência o desprezo dos MIS pela gestão, em favor de redes informais de contactos. Proposição: «As políticas para os SPCP devem considerar os mecanismos de coordenação do trabalho que determinam a estrutura formal, regulam os fluxos de informação e condicionam o sistema informal de autoridade». 
Mintzberg (1979: 218) propõe a hipótese da configuração que declara que 'a estruturação organizacional eficaz requer consistência interna entre os parâmetros de concepção da organização'. Proposição: «As políticas para os SPCP devem ter em atenção a verificação da hipótese da configuração e, como tal, garantir a consistência entre a estratégia do negócio, a estratégia de operações, a estratégia para os SI/TI e a estrutura organizacional».

\section{CONCLUSÕES}

A maior parte das decisões relativas à selecção ou concepção e implementação dos SPCP continuam a ser tomadas segundo: perspectivas funcionais; práticas mais populares e modas do mês; opções exclusivamente proporcionadas pelos vendedores de soluções informáticas genéricas; perspectivas operacionais, de curto prazo e mecanicistas; linhas de actuação das escolas tradicionais de gestão, etc. A implementação desta forma de proceder tem levado, muitas vezes, a um fraco nível de desempenho dos SPCP.

Este artigo analisou as abordagens que diversos ramos do conhecimento efectuam sobre factores determinantes do posicionamento dos SPCP no seio da organização e, consequentemente, do seu desempenho. Para além disso, foram consideradas teorias rivais, com vista à construção de um cenário de discussão mais rico. Com base nesta triangulação do conhecimento de diversas fontes, construiu-se um contexto analítico de posicionamento dos SPCP que se procurou que fosse pluralístico e isento (Figura 5).

Julgamos ser lícito concluir da análise efectuada que a escolha ou concepção e implementação dos mecanismos de controle da produção mais adequados não é um problema, nem da produção, nem de controle, mas sim um problema a ser abordado no contexto da estruturação das organizações, segundo uma perspectiva contingencial. Como tal, a solução para o problema do desempenho dos SPCP deve ser procurada fora das suas fronteiras tradicionais, favorecendo uma perspectiva holística da organização. 
Fig. 5

IMPACTO E INTERESSE DO CONTEXTO

ANALÍTICO DESENVOLVIDO

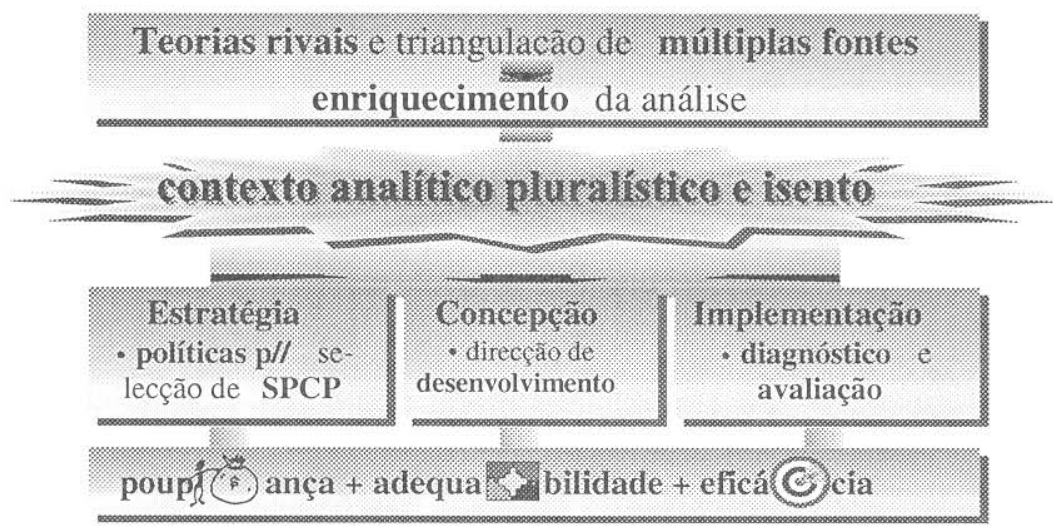

Estamos convictos que só assim se podem identificar as opções de SPCP mais adequadas, explicar o sucesso ou falha de determinados paradigmas e minimizar o risco de antecipar comportamentos destes procedimentos, como está resumido na Figura 5. Como principais desvantagens da abordagem, citam-se a possibilidade de risco de complicações e complexidade desnecessárias e a potencial desfocagem, derivadas do âmbito alargado da mesma.

Finalmente, como recomendações para trabalho futuro têm-se as seguintes: i) desenvolver a dimensão horizontal do contexto descritivo; ii) detalhar as proposições provenientes da análise efectuada; iii) caracterizar os paradigmas alternativos de planeamento e controle da produção; iv) identificar correlações entre os paradigmas de PCP e proposições, de modo a estabelecer um padrão previsível de resultados que possa à posteriori ser comparado com padrões provenientes do estudo de casos reais e, v) avaliar a validade externa do modelo através de uma técnica de generalização analítica do padrão teórico de resultados (Yin, 1994:30-2, 36), i.e., face às possibilidades de replicação literal e teórica proporcionada pelos padrões de resultados provenientes do estudo de casos. 


\section{REFERÊNCIAS BIBLIOGRÁFICAS}

ANSOFF, H. (1991), "Critique of Henry Mintzberg's "The design school: reconsidering the basic premises of strategic management"', Strategic management journal, vol. $12,449-461$.

AYERS, J. B. (1995), "What smokestake industries can tell us about reengineering", Information strategy: the executive's journal, vol. 11, no. 2, 20-26.

BURBIDGE, J. (1996), Period batch control, Oxford University Press, USA.

BURCHER, P. \& STEVENS, K. (1996), "Measuring up to world class manufacturing", BPICS control, February 1996, 17-21.

BURGOYNE, J. G. (1989), A behavioural science perspective on operational research practice, in: Jackson, M. C., Keys, P. and Cropper, S. A. (eds.), Operational research and the social sciences, Plenum Press, New York, 3-12.

BUTTERY, E. A. (1989), "New paradigm research as part of a holistic production planning and control system for a carpet manufacturing firm in Scotland", in: Jackson, M. C., Keys, P. and Cropper, S. A. (eds.), Operational research and the social sciences, New York, Plenum Press, 319-324.

CHECKLAND, P. B. (1989), "OR and social science: fundamental thoughts. In: Jackson, M. C., Keys, P. and Cropper", S. A. (eds.), Operational research and the social sciences, Plenum Press, New York, 35-41.

DAVIES, A., KENNERLY, M., KOCHAR, A., OLDHAM, K., OLIVER, S. \& THACHER, M. (1996), Improving your business through effective manufacturing and control systems, UMIST Draft Workbook.

DAWES, F. (1995), "Redefining strategy: a core competence approach to linking business and operations strategy". In: Draaijer, D., Boer, H. and Krabbendam (eds.), $2^{\text {nd }}$ international conference of the european operations management association, University of Twente, Netherlands, 91-96.

DEAR, A. (1988), Working towards Just-in-Time, London, Kogan Page Ltd.

DUNCAN, R. (1972), "Characteristics of organisational environments and perceived environmental uncertainty", Administrative science quarterly, vol. 17, 313-327.

EARL, M. (1989), Management strategies for information technology, Great Britain, Prentice Hall Europe.

EDWARDS, C. \& PEPPARD, J. (1994), "Business process redesign: hype, hope or hypocrisy?". Journal of information technology, vol. 9, no. 4, 251-266.

EZINGEARD, J. \& GRIEVE, B. (1995), "Issues of users' perception in performance assessment of manufacturing information systems", in Stockton, D. and Wainwright, C. (eds.), Advances in manufacturing technology IX - proceedings of the eleventh national conference on manufacturing research, United Kingdom, De Montfort University, Leicester, 467-471. 
FIEDLER, K., GROVER, V. \& TENG, J. (1994), "Information Technology-enabled change: the risks and rewards of business process redesign and automation", Journal of information technology, vol. 9, no. 4, 267-275.

GOODRIDGE, M. (1988), "Managing operations: into the 1990s", Management decision, vol.26, no. 1, 5-10.

HAMMER, M. (1990), "Reengineering work: don't automate, obliterate", Harvard business review, vol. 68, no. 4, 104-112.

HATCH, M. (1997), Organisation theory: modern, symbolic and postmodern perspectives, USA, Oxford University Press.

HAYES, R. \& WHEELWRIGHT, S. (1984), Restoring our competitive edge: competing through manufacturing,USA, John Wiley and Sons, Inc..

HENDERSON, S. (1997), "IT implementation as an objective exercise". BPICS control, Dec 1996/Jan 1997, 17-20.

HILL, T. (1993), Manufacturing Strategy: the strategic management of the manufacturing function, MacMillan Press, Ltd, London.

HUM, S. \& SIM, H. (1996), "Time-based competition: literature review and implications for modelling", International journal of operations \& production management, vol. 16, no. 1, 75-90.

JELINEK, M. (1977), "Technology, organisations and contingency", Academy of management review, vol. 2, no. 1, 17-26.

JIH, W. J. K. \& OWINGS, P. (1995), "From in search of excellence to business process reengineering: the role of information technology", Information strategy: the executive's journal, vol.11, no. 2, 6-19.

JOHNSON, G. \& SCHOLES, K. (1997), Exploring corporate strategy:text and cases, UK, Prentice-Hall Europe.

KAPLAN, R. (1984), "Yesterday's accounting undermines production", Harvard business review, July-August 1984, 95-101.

KAPLAN, R. (1986), "Accounting lag: the obsolescence of cost accounting systems", California management review, vol XXVIII, n², Winter 1986, 174-199.

KAPLAN, R. \& NORTON D. (1992), "The balanced scorecard - measures that drive performance", Harvard business review, January-February 1992,71-79.

KAPLAN, R. \& NORTON D. (1993), "Putting the balanced scorecard to work", Harvard business review, September-October 1993, 134-147.

KAPLAN, R. \& NORTON D. (1996), "Using the balanced scorecard as a strategic management system", Harvard business review, January-February 1996, 75-85.

KHANDWALLA, P. (1977), The design of organisations, USA, Harcourt Brace Jovanovich, Inc.

LATHAM, D. (1981), "Are you among MRP's walked wounded?" Production and inventory management, Third Quarter, 33-41.

LAWRENCE, A. (1986), "Are CAPM systems too complex?", Industrial computing, September, 13. 
LEHANEY, B. (1989), A scientific approach to methodology, In: Jackson, M. C., Keys, P. and Cropper, S. A. (eds.), Operational research and the social sciences, Plenum Press, New York, 177-182.

LEHANEY, B. \& VINTEN, G. (1994), “"Methodology": an analysis of its meaning and use". Work study, vol. 43, no. 3, 5-8.

LEWIS, P. J. (1989), From measurement and control to learning and redirection: using 'soft' systems thinking in the evaluation of human action. In: Jackson, M. C., Keys, P. and Cropper, S. A. (eds.), Operational research and the social sciences, New York, Plenum Press, 253-258.

LOCKETT, G. (1989), Information systems and operational research. In: Jackson, M. C., Keys, P. and Cropper, S. A. (eds.), Operational research and the social sciences, Plenum Press, New York, 445-450.

MAIR, A. (1994), "Honda's global flexifactory network", International journal of operations \& production management, vol. 14, no. 3, 6-23.

MARTIN, D. (1989), Practical issues in planning: a case of methodology. In: Jackson, M. C., Keys, P. and Cropper, S. A. (eds.), Operational research and the social sciences, New York, Plenum Press, 479-484.

MCALLISTER, H. \& CARLISLE, B. (1994), Linking strategy to the evaluation of MRPII systems. In: Platts, K., Gregory, M. and Neely, A. (eds.), Irst international conference of the European operations management association, United Kingdom, University of Cambridge, 541-542.

MERTINS, K., EDELER, H. \& SAUER, O. (1994), "The company-specific coreprocess". In: Platts, K., Gregory, M. and Neely, A. (eds.), lrst international conference of the European operations management association, University of Cambridge, United Kingdom, 253-258.

MILLARD, R. (1989), "Is MRP training aimed in the right direction", Production and inventory management journal, Second Quarter, 22-26.

MILLER, J. (1981), "Fit production systems to the task", Harvard business review, January-February 1981, 145-154.

MINTZBERG, H. (1979), The structuring of organisations. Prentice-Hall International Inc., USA.

MINTZBERG, H. (1981), "Organisation design: fashion or fit?", Harvard business review, January-February 1981, 103-116.

MINTZBERG, H. (1985), "Of strategies, deliberate and emergent", Strategic management journal, vol. 6, 257-272.

MINTZBERG, H. (1987), "Crafting strategy", Harvard business review, July-August 1987, 66-75.

MINTZBERG, H. (1990), "The design school: reconsidering the basic premises of strategic management", Strategic management journal, vol. 11, 171-195. 
NANNI, A., DIXON, J. \& VOLLMAN, T. (1992), "Integrated performance measurement: management accounting to support the new manufacturing realities", Journal of management accounting research, vol. 4, Fall 1992, 1-19.

NEWELL, S., CLARK, P., SWANN, J. \& SHARIFI, S. (1991), Organisation-andtechnology systems (OATS): "The case of computer aided production management (CAPM)", in: Spurgeon, D. and Apampa, O. (eds.), Advances in manufacturing technology VI-proceedings of the seventh national conference on production research, Hatfield Polytechnic, United Kingdom, 261-265.

OHNO, T. \& MITO, S. (1988), Just-in-time for today and tomorrow, USA, Productivity Press, Inc..

PATTON, M. (1987), How to use qualitative methods in evaluation, USA, Sage Publications.

PIDD, M. (1988), "From problem-structuring to implementation", Journal of the operational research society, vol. 39 , no. $2,115-121$.

PEPPARD, J. (ed.) (1993), I .T. strategy for business, Pitman Publishing, Great Britain.

PETERS, T. \& WATERMAN, R. (1995), In search of excellence: lessons from America's best run companies, Great Britain, Harper Collins Publishers.

PLATTS, K., \& GREGORY, M. (1990), "Manufacturing audit in the process of strategy formulation", International journal of operations \& production management, vol. 10, no. 9, 5-26.

PORTER, M. (1985), Competitive advantage: creating and sustaining superior performance. USA, The Free Press.

PORTER, M. (1986), "Changing the patterns of international competition", California management review, vol. XXVIII, no.2, Winter, 9-40.

PORTER, J. K., JARVIS, P., LITTLE, D., LAAKMANN, J., HANNEN, C. \& SCHOTTEN, M. (1996), "Production planning and control in Germany", International journal of operations \& production management, vol. 16, no. 1, 27 39.

PRAHALAD, C. \& HAMEL, G. (1990), "The core competence of the corporation", Harvard business review, May-June 1990, 79-91.

PRIMROSE, P. (1990), "Selecting and evaluating cost-effective MRP and MRPII", International journal of operations \& production management, vol. 10, no. 1, 5166.

RHODES, D. J. (1991), "The facilitator - an organizational necessity for the successful implementation of IT and operations strategies, Computer-integrated manufacturing systems, vol. 4, no. 2, 109-113.

ROBB, F. (1989), The limits to human organisation: the emergence of autopoietic systems. In: Jackson, M. C., Keys, P. and Cropper, S. A. (eds.), Operational research and the social sciences, New York, Plenum Press, 247-251.

ROBBINS, S. (1990), Organisation theory: structure design and applications. $3^{\text {rd }} \mathrm{ed.}$, USA, Prentice-Hall, Inc.. 
ROBSON, C. (1993), Real world research, UK, Blackwell Publishers Inc..

SAP (1994). "Success story...", Folhetos do pacote de divulgação do sistema R3, SAP AG, Waldorf, Germany.

SIEHL, C. \& MARTIN, J. (1984), The role of symbolic management: how can managers effectively transmit organisational culture? In: Hunt, J., Hosking, D., Schriesheim, C. and Steward, R. (eds.), Leaders and managers: international perspectives on managerial behaviour and leadership. Pergamon, New York.

SKINNER, W. (1985), Manufacturing: the formidable competitive weapon, USA, John Wiley \& Sons, Inc.

SLACK, N. (1991), The manufacturing advantage: achieving competitive manufacturing operations, London, UK, Mercury Books, Gold Arrow Publications Ltd.

SMITHSON, S. (1989), Information systems evaluation: understanding subjective assessments. In: Jackson, M. C., Keys, P. and Cropper, S. A. (eds.), Operational research and the social sciences, New York, Plenum Press, 415-420.

STACEY, R. (1995), Managing caos: dynamic business strategies in an unpredictable world, London, Kogan Page, Ltd..

STANLEY, D. (1989), The organisation as an information system. In: Jackson, M. C., Keys, P. and Cropper, S. A. (eds.), Operational research and the social sciences, New York, Plenum Press, 427-432.

SWEENEY, M. \& SZWEJCZEWSKI, M. (1995), Manufacturing standards of performance for success. In: Time for success - proceedings of the $30^{\text {th }}$ annual BPICS conference, Birmingham, United Kingdom, 53-63.

SYMONS, V. \& WALSHAM, G. (1989a), "Information systems". In: Jackson, M. C., Keys, P. and Cropper, S. A. (eds.), Operational research and the social sciences, Plenum Press, New York, 405-407.

SYMONS, V. \& WALSHAM, G. (1989b), "Evaluation of information systems: a case study of a manufacturing organisation". In: Jackson, M. C., Keys, P. and Cropper, S. A. (eds.), Operational research and the social sciences, Plenum Press, New York, 421-426.

TAMPOE, M. (1994), "Exploiting the core competences of your organisation", Long range planning, vol. 27 , no. 4, 66-77.

TOMLINSON, R. (1989), "Managing the OR-management interface". In: Jackson, M. C., Keys, P. and Cropper, S. A. (eds.), Operational research and the social sciences, Plenum Press, New York, 613-616.

TUNALY, C. (1992), "Manufacturing strategy - plans and business performance", International journal of operations \& production management, vol. 12, no. 3, 424.

VILAS-BOAS DA SILVA, J. M. (1994), "Contribuição da estratégia da produção para a estratégia do negócio", Gestão e Desenvolvimento, no. 3, 41-75.

VILAS-BOAS DA SILVA, J. M. (1995), "Desenvolvimento de sistemas de informação de suporte informático", Gestão e Desenvolvimento, no. 4, 127-157. 
VILAS-BOAS DA SILVA, J. M. \& KAY, J. M. (1998), "Assessment of production planning and control systems". In: Neely, A. and Waggoner, D. (eds.), Performance measurement: theory and practice, Centre for Business Performance, The Judge Institute of Management Studies, Cambridge University, UK, 567-575.

WARD, J. \& GRIFFITHS, P. (1996), Strategic planning for information systems, England, John Wiley and Sons Ltd. $2^{\text {nd }}$ ed.

WARD, M., CHEESE, P., THAYER, B., SAKUDA, I., JONES, D., DELBRIDGE, R., LOWE, J. \& OLIVER, N. (1993), The lean enterprise benchmarking project, Arthur Andersen Consulting Report.

WOODWARD, J. (1994), Industrial organisation: theory and practice. $2^{\text {nd }}$ ed. reissued, Great Britain, Oxford University Press.

YIN, R. (1994), Case study research: design and methods. $2^{\text {nd }}$ ed., USA, Sage Publications, Inc.. 